\title{
Targeting SHP-1-STAT3 signaling: A promising therapeutic approach for the treatment of cholangiocarcinoma
}

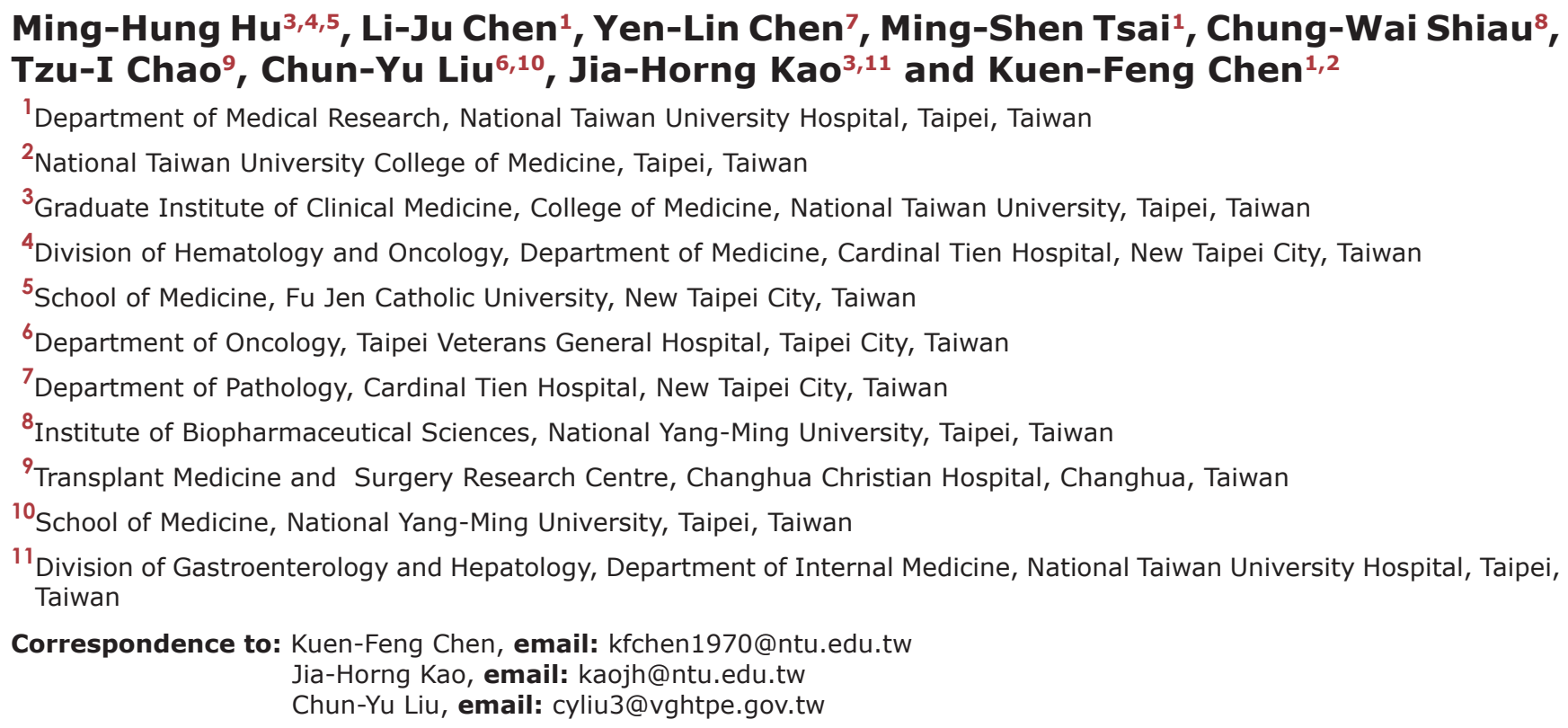

Keywords: cholangiocarcinoma, SC-43, STAT3, SHP-1, inflammatory cancer

Received: May 09, $2016 \quad$ Accepted: April 26, $2017 \quad$ Published: May 10, 2017

Copyright: Hu et al. This is an open-access article distributed under the terms of the Creative Commons Attribution License 3.0 (CC BY 3.0), which permits unrestricted use, distribution, and reproduction in any medium, provided the original author and source are credited.

\section{ABSTRACT}

Sorafenib is a multiple kinase inhibitor which targets Raf kinases, VEGFR, and PDGFR and is approved for the treatment of hepatocellular carcinoma (HCC). Previously, we found that p-STAT3 is a major target of SC-43, a sorafenib derivative. In this study, we report that SC-43-induced apoptosis in cholangiocarcinoma (CCA) via a novel mechanism. Three CCA cell lines (HuCCT-1, KKU-100 and CGCCA) were treated with SC-43 to determine their sensitivity to SC-43-induced cell death and apoptosis. We found that SC-43 activated SH2 domain-containing phosphatase 1 (SHP-1) activity, leading to p-STAT3 and downstream cyclin B1 and Cdc2 downregulation, which induced G2-M arrest and apoptotic cell death. Importantly, SC-43 augmented SHP-1 activity by direct binding to $\mathrm{N}-\mathrm{SH} 2$ and relief of its autoinhibition. Deletion of the $\mathrm{N}-\mathrm{SH} 2$ domain (dN1) or point mutation (D61A) of SHP-1 counteracted the effect of SC-43-induced SHP-1 phosphatase activation and antiproliferation ability in CCA cells. In vivo assay revealed that SC-43 exhibited xenograft tumor growth inhibition, p-STAT3 reduction and SHP-1 activity elevation. In conclusion, SC-43 induced apoptosis in CCA cells through the SHP-1/STAT3 signaling pathway.

\section{INTRODUCTION}

Cholangiocarcinoma (CCA) is the second most common hepatic malignancy after hepatocellular carcinoma (HCC) and the most common biliary malignancy, accounting for $3 \%$ of all gastrointestinal tumors [1]. CCAs are epithelial malignancies that arise from cholangiocytes and are characterized by aggressive behavior and advanced clinical stage. Although CCA is not a common malignancy, the overall incidence of CCA has increased significantly over the past three decades [2-4]. Meanwhile, the mortality from CCA is still increasing [4]. Currently, not a single 
targeted agent has been approved for the treatment of CCA. Treatment options for CCA are limited, and cytotoxic chemotherapy remains the only choice for unresectable metastatic CCA. However, CCA is generally refractory to most chemotherapy, and 5-year survival rate is extremely poor, remaining at $10 \%[5,6]$. The unmet medical need in patients with CCA remains a great clinical challenge. Owing to the unsatisfactory therapeutic outcomes under the current standard management, development of novel agents for treatment of CCA is undoubtedly an important mission.

CCA is an endemic disease, the worldwide incidence of which varies greatly $[7,8]$. Incidence in regions such as Thailand in Southeast Asia (as high as 113 per 100,000 in men and 50 per 100,000 in women) is about one hundred times more than that in most Western countries. There are several well-established risks associated with CCA development, including infestation with the liver fluke Opisthorchis viverrini, hepatolithiasis, primary sclerosing cholangitis (PSC), choledochal cysts, liver cirrhosis, alcohol consumption, tobacco use, and chronic viral hepatitis $[6,9,10]$. Generally speaking, chronic inflammation significantly contributes to CCA formation. According to epidemiologic and population-based studies, CCA incidence is still increasing in Thailand and is strongly correlated with the high prevalence of infection with the parasite O.viverrini $[7,11]$. These studies have provided clues to the role of environmental factors in the etiology and pathogenesis of cholangiocarcinoma. O.viverrini infection represents a classical model for CCA that interprets the role of inflammation in CCA carcinogenesis well [12, 13].

Cancer-associated inflammation is marked by the presence of specific inflammatory cells and inflammatory mediators, including cytokines and chemokines.

Signal transducers and activators of transcription 3 (STAT3) belong to a family of transcription factors that relay cytokine receptor-generated signals into the nucleus. STAT3 is activated by the cytokine IL-6 as well as other growth factors, including epidermal growth factor receptor (EGFR), fibroblast growth factor receptor (FGFR), and platelet-derived growth factor receptor (PDGFR) through tyrosine phosphorylation [14]. After dimerization, STAT3 translocates into the nucleus where it activates gene transcription. STAT3 signaling mediates cell growth, proliferation, inflammatory cytokine production, cell invasion and migration. Stimulations such as O.viverrini infection or PSC cause cholestasis and chronic inflammation of the bile duct, which can induce a variety of cytokines including IL-6, platelet-derived growth factor (PDGF), and epidermal growth factor (EGF) $[15,16]$. This inflammatory cascade activates STAT3, leading to overproduction of bile duct epithelium growth factor, thus promoting CCA initiation. Because of the role of STAT3 in inflammation and cancer development, targeting STAT3 is a rational treatment strategy for CCA.

Sorafenib acts as a multiple kinase inhibitor that works against rapidly accelerated fibrosarcoma (Raf) kinases, vascular endothelial growth factor receptor (VEGFR), and PDGFR, among others. Boris et al. revealed that sorefenib inhibits CCA cells by downregulating STAT3 signaling [17]. Previously, we discovered that SHP-1, a nonreceptor protein tyrosine phosphatase (PTP) that negatively regulates p-STAT3, is also a direct target of sorafenib [18, 19]. Accordingly, we have synthesized a series of sorafenib analogs which resemble sorafenib structure closely but have no kinase inhibition activities. Among these derivatives, SC-43 was found to be a more potent SHP-1 agonist than sorafenib. Our earlier study demonstrated that SC-43 had therapeutic potential in HCC treatment [18]. Based on this preclinical success, $\mathrm{SC}-43$ is currently poised to enter a phase I clinical trial for treatment of HCC.

Given the evidence for the antiproliferative ability of SC-43 in CCA through STAT3 inhibition, we hypothesize that it might have a therapeutic effect in CCA. In the present study, we assessed the effect of SC-43 on CCA cells and investigated the underlying molecular mechanism.

\section{RESULTS}

\section{Novel sorafenib derivative $\mathrm{SC}-43$ induced apoptosis in CCA cells by inducing G2-M arrest}

In CCA cells from representative tumor tissue from a CCA patient, $\mathrm{p}$-STAT3 showed positive expression in the tumor part (Figure 1A, left) compared with normal tissue part (Figure 1A, right). SC-43 is a novel derivative of sorafenib. To investigate the apoptosis effect induced by SC-43, we tested three CCA cell lines: HuCCT-1, KKU-100, and CGCCA. First, as shown in Figure 1B, MTT assay revealed the anti-proliferative effects of SC-43 in CCA cell lines in a dose-dependent manner after treating 24, 48 and 72 hours respectively. Next, flow cytometry analysis showed increased sub-G1 cells and G2-M arrest, indicating SC-43 induced differential apoptotic effects in these cell lines, which corresponds with the MTT assay (Figure 1C). In addition, CCA cells treated with $\mathrm{SC}-43$ demonstrated significant increase in cleaved caspase- 3 and PARP level in western blot analysis after exposure for 24 hours (Figure 1D). Taken together, these data indicated that SC43 has a significant effect to induce G2-M arrest, on CCA cell, leading to apoptosis and growth inhibition.

\section{SC-43 induces apoptosis with downregulation of STAT3 in CCA cells}

Next, we examined whether STAT3 had a relationship with $\mathrm{SC}-43$-induced apoptosis in CCA cells. In Figure 2A, SC-43 was demonstrated to dosedependently downregulate p-STAT3 and its downstream mediators, survivin and cyclin D-1. STAT3 level did not diminish after SC-43 treatment. Furthermore, SC43-induced downregulation of the p-STAT3 signaling 
A
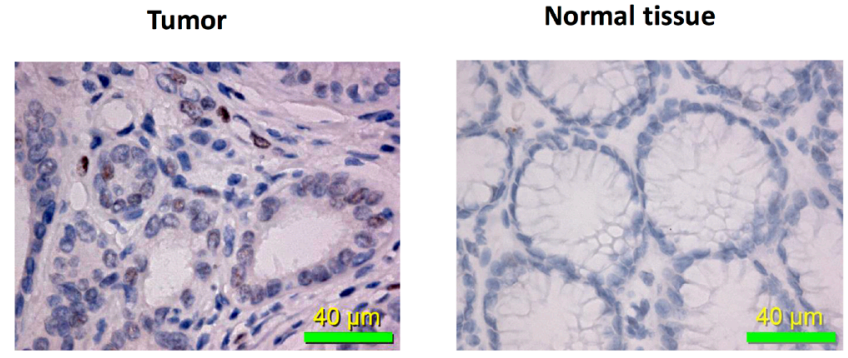

B

HuCCT-1

KKU-100

CGCCA
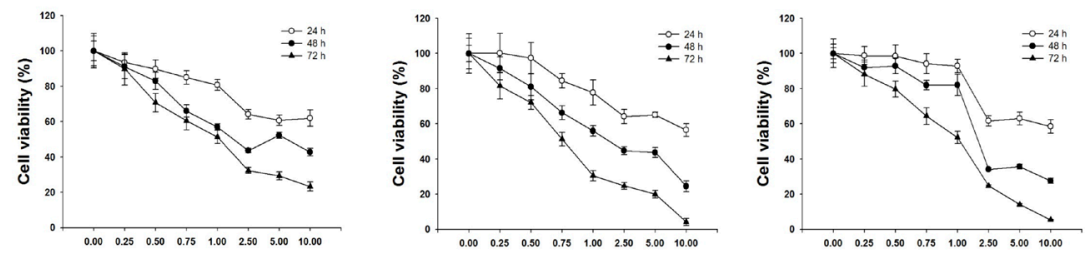

C SC43-0 $\mu \mathrm{M}$
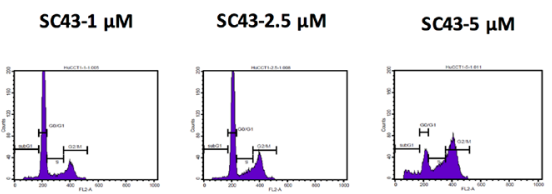

SC43-10 $\mu \mathrm{M}$
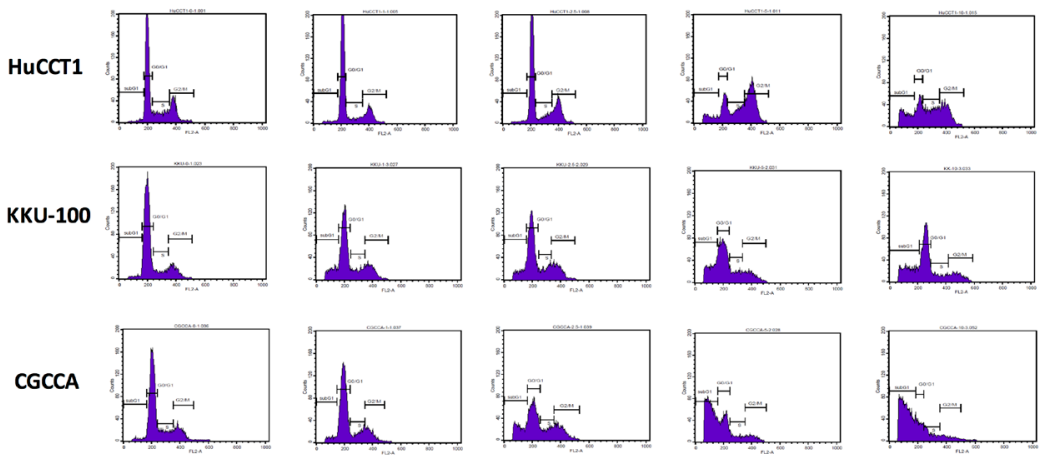

HuCCT1

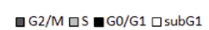

KKU-100

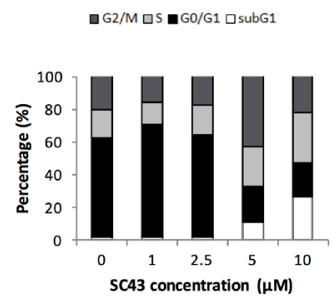

a G2/M पS G0/G1 asubG1

CGCCA
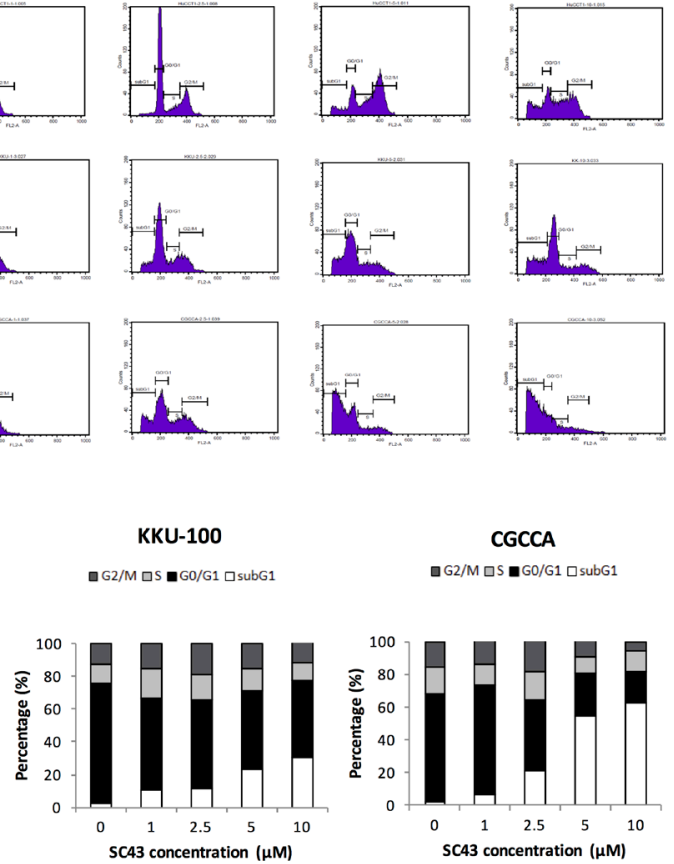

D
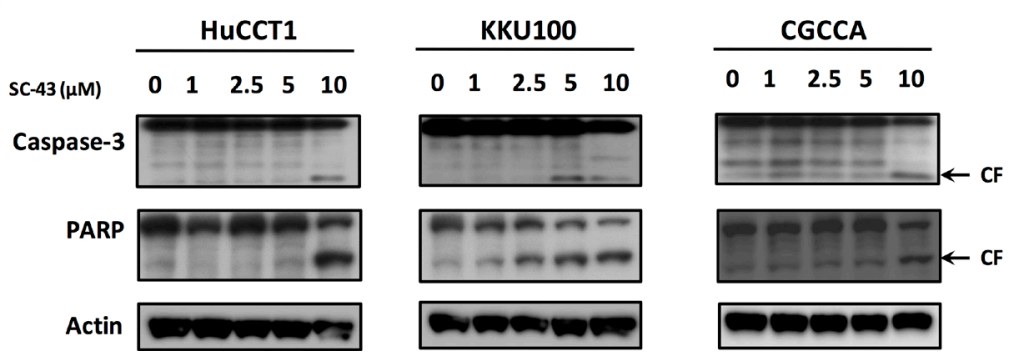

Figure 1: SC-43 exerts anti-proliferative and apoptosis-inducing effects in cholangiocarcinoma (CCA) cells. SC-43, a derivative of sorafenib induces apoptosis in CCA cell lines. (A) immunohistochemical (IHC) staining for p-STAT3 in CCA tumor (left), compared with normal tissue part (right). (B) dose-escalation effects of SC-43 on cell viability. Cells were exposed to SC-43 at the indicated doses for 24, 48, and 72 hours respectively and cell viability was assessed by MTT assay. Points, mean; bars, SD $(n=9)$. (C) effects of SC-43 on apoptosis. Cells were exposed to SC-43 at the indicated doses for 24 hours and number of apoptotic cells was determined by flow cytometry. Columns, mean; bars, SD $(n=3)$. (D) SC-43-induced apoptosis-related signals in cells. 
pathway in KKU-100 was time-dependent (Figure 2B), as well as in HuCCT-1 and CGCCA (Supplementary Figure 1). In STAT3 overexpressing cholangiocarcinoma cells, inhibition of p-STAT3 after SC-43 treatment was reduced. The apoptosis in STAT3 overexpressing cancer cells was reversed as well (Figure 2C). We further explored the role of SC-43 involving G2-M arrest. We performed western blot analysis of cell extracts to compare the levels of expression of the cyclin B1 and Cdk1 (Cdc2), the major regulatory protein and kinase for progression from $\mathrm{G} 2$ to $\mathrm{M}$ phase. Western blotting demonstrated that the levels of the cyclin $\mathrm{B} 1$ and $\mathrm{Cdc} 2$ protein were markedly reduced after SC-43 treatment (Figure 2D). In summary, we hypothesized that SC-43 had an antiproliferative effect on CCA cells through inhibiting the STAT3 pathway, as well as $\mathrm{G} 2-\mathrm{M}$ arrest by inhibiting cyclin B1 and $\mathrm{Cdc} 2$

\section{Validation of the SHP-1/p-STAT3 pathway as a molecular determinant of SC-43 induced CCA cell apoptosis}

In our previous study, we found that SC-43 induced cancer cell apoptosis through upregulation of SHP-1 and downregulation of p-STAT3, suggesting that SHP-1 is a target of SC-43 [18]. Therefore, in this study, we assumed that SHP-1 may also play a role in the biological reaction associated with apoptosis induced by $\mathrm{SC}-43$ in CCA cells. First, we tested SHP-1 phosphatase activity in the above three CCA cell lines: HuCCT-1, KKU-100, and CGCCA. As illustrated in Figure 3A, SHP-1 activity was universally increased in all cell lines after SC-43 treatment. Furthermore, SC-43 increased the phosphatase activity of SHP-1 in IP-SHP-1 cell lysate from HuCCT-1 cells, suggesting that SC-43 activates SHP-1 through direct interaction with SHP-1 proteins (Figure 3B). To validate the role of SHP-1 in mediating SC-43-induced apoptosis, we utilized PTPIII, a SHP-1 specific inhibitor. The protective effects of SC-43-induced apoptosis in HuCCT-1 and KKU-100 cells were noted after PTPIII administration (Figure 3C). After HuCCT-1 cells were transfected with SHP-1 siRNA, SC-43-induced apoptosis was reduced significantly in SHP-1-silencing HuCCT-1 cells, comparing to cells transfected with control si-RNA (Figure 3D, left). Then, we generated HuCCT-1 cells with constitutive, ectopic expression of myc-tagged SHP-1. SC-43 treatment in HuCCT-1 with high levels of SHP-1 showed more inhibition of p-STAT3 and more cell apoptosis, compared to cells transfected with empty vectors (Figure 3D, right). Taken together, these results suggested that SC-43 mediates the apoptotic effect in CCA cells through p-STAT3 inhibition by activating SHP-1 activity.

\section{SC-43 relieves autoinhibition of SHP-1 by interfering with the inhibitory $\mathrm{N}-\mathrm{SH} 2$ domain}

As the activity of SHP-1 was strongly regulated by the auto-inhibited 3D structure, we constructed wild- type, deletion of N-SH2 (dN1), and D61 single mutant (D61A) of SHP-1 to investigate the effect of SC-43 on different SHP-1 statuses (Figure 4A). The dN1 and D61A mutants resemble open (non-autoinhibition) forms. As demonstrated in Figure 4B, SC-43 induced significantly less p-STAT3 downregulation and apoptosis in HuCCT-1 cells expressing the $\mathrm{dN} 1$ and D61A mutants than in the wild-type control, suggesting that $\mathrm{N}-\mathrm{SH} 2$ and PTPase catalytic domain are important for SC-43 induced effects. The conformational change of SHP-1 induced by dN1 and D61A counteracted the SC-43 effect. Furthermore, dose-escalation study of transfection of dN1 and D61A suppressed the expression of p-STAT3 and decreased SC-43-induced p-STAT3 inhibition (Figure 4C). These results indicated that relieved SHP-1 counteracts the SC43-induced anti-CCA effect. SC-43, therefore, potentially relieves auto-inhibition of SHP-1, leading to p-STAT3 signal downregulation.

\section{Effect of SC-43 on CCA xenograft tumor growth in vivo}

In order to confirm that using SC-43 to inhibit p-STAT3 has potentially clinical relevant implications in CCA, we established a CCA xenograft model to evaluate the effect of SC-43 in vivo. In our study, SC-43 not only inhibited HuCCT-1 xenograft tumor size but also tumor weight significantly (Figure 5A). The side effect of SC-43 was well-tolerated and no observable signs of toxicity were noted. All the experimental animals had stable body weights throughout the whole treatment course (Figure 5B). The protein expression was checked to confirm the correlation between the biological response observed in vivo and the molecular mechanism discovered in vitro. The p-STAT3 level was reduced after SC-43 treatment. Moreover, SC-43 increased SHP-1 phosphatase activity compared with the control group (Figure 5C). A schema summarizing the molecular mechanism of SC-43 in sensitive CCA cells is presented in Figure 5D: SC-43 activates SHP-1 phosphatase by impairing the inhibitory N-SH2 domain, and contributes to p-STAT3, downstream cyclin B1 and $\mathrm{Cdc} 2$ downregulation, leading to G2-M arrest and cancer cell apoptosis.

\section{DISCUSSION}

CCA is a fetal disease with dismal prognosis that lacks efficient medical management. There are few clinical trials incorporating molecularly targeted agents reported in this aggressive biliary tract malignancy. Therefore, novel treatment choice is of urgent need. In this article, we introduced a novel sorafenib derivative, SC-43, with potential therapeutic effects in CCA. We revealed that SC-43 demonstrates a significant anti-proliferative effect in CCA through p-STAT3 pathway inhibition. SHP-1 is a major determinant in the apoptosis effect of SC-43. By 
upregulating SHP-1, SC-43 induced SHP-1-dependent p-STAT3 downregulation. SC-43 directly interacts with SHP-1 SH2 domain and relieves its auto-inhibition structure. These findings not only increase current understanding of the SHP-1/STAT3 pathway but also support the rationale for targeting SHP-1 in the future development of therapies for CCA.
Chronic inflammation triggers cellular events that can promote malignant transformation of cells and carcinogenesis. Several inflammatory mediators, such as IL-6 and TGF- $\beta$, have been shown to participate in both the initiation and progression of cancer. STAT3 is crucial in initiating and maintaining a procarcinogenic inflammatory microenvironment, both at the beginning
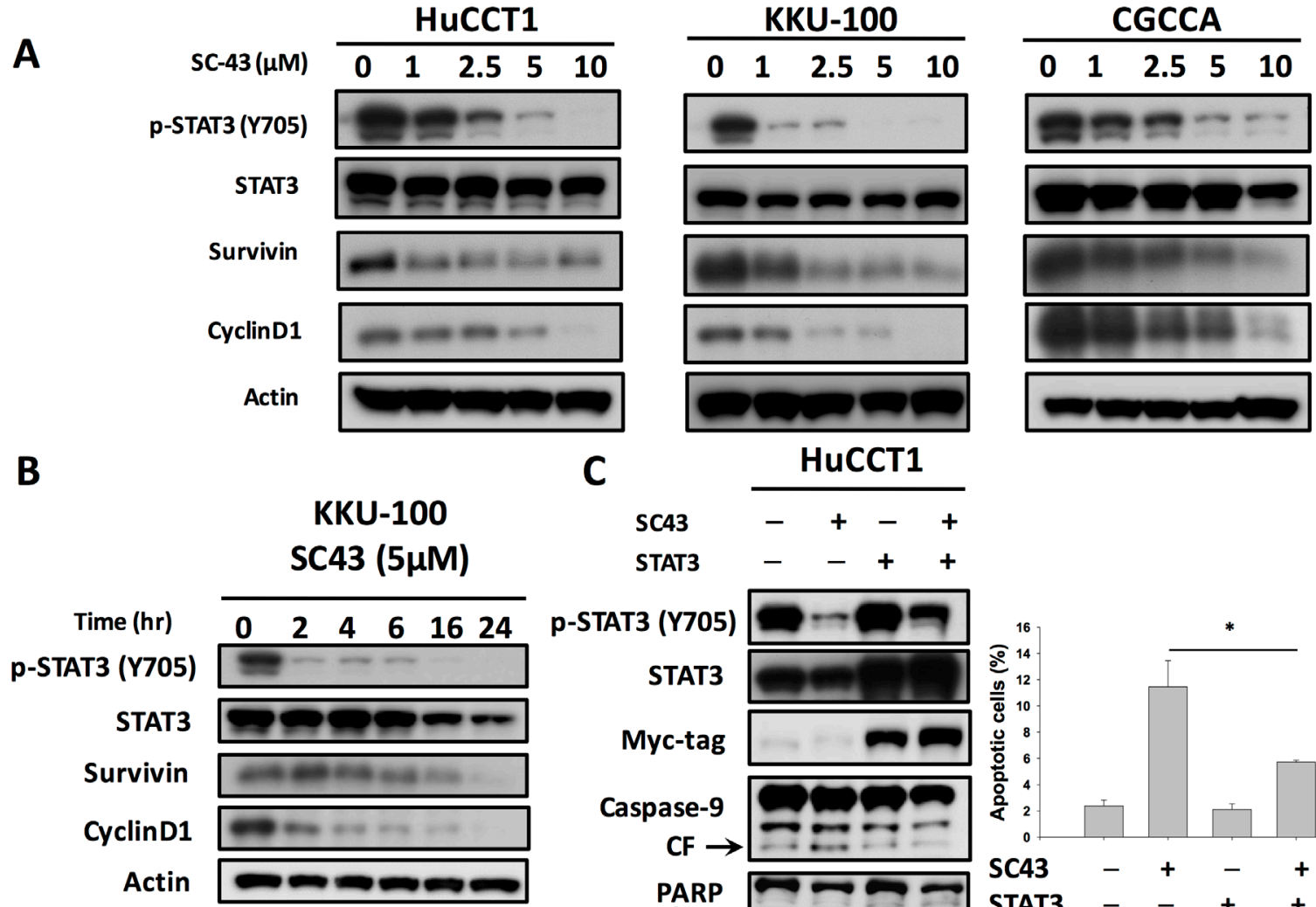

p-STAT3 (Y705)
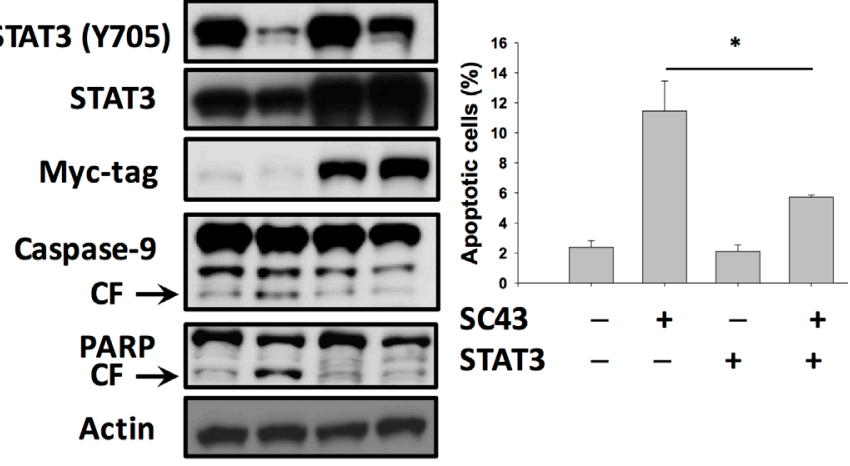

D
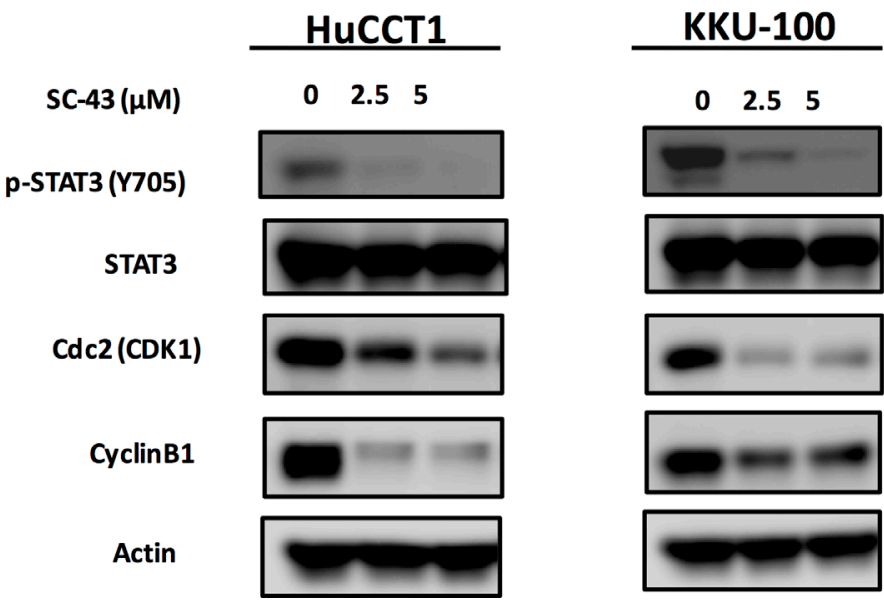

Figure 2: Inhibition of p-STAT3 determines the sensitizing effects of SC-43 in CCA cells. (A) dose-dependent effects of SC-43 on STAT3-related proteins. Cell were treated with SC-43 at the indicated doses for 24 hours.(B) SC-43 induced p-STAT3 inactivation in a time-dependent manner. (C) STAT3 reverses the apoptotic effect of SC-43. HuCCT-1 cells transiently expressing STAT3 with Myc-tag were treated with SC-43 at $5 \mu \mathrm{M}$ for 24 hours and the percentage of apoptosis was measured by sub-G1 analysis. (D) western blot analysis of the cyclin B1 and Cdk1 (Cdc2) with SC-43 at the indicated doses for 24 hours. Columns, mean; bars, SD $(n=3) ; * P<0.05$. 

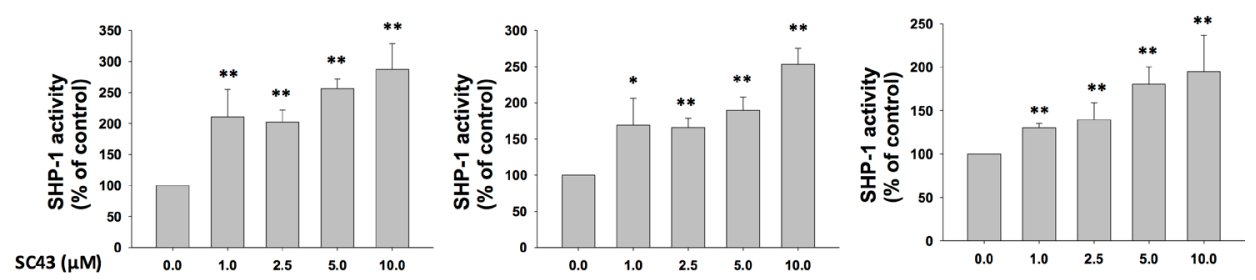

B

C

IP:SHP-1

HuCCT1

KKU100
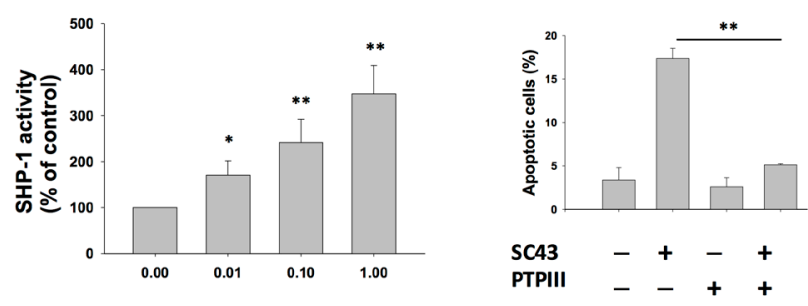

p-STAT3 (Y705) $\mathrm{O}=\mathrm{B}$

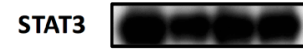

Caspase-9
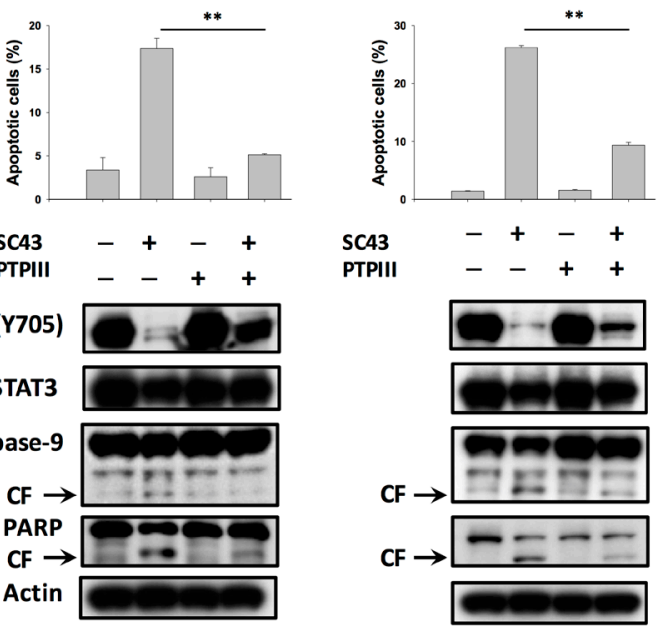

D
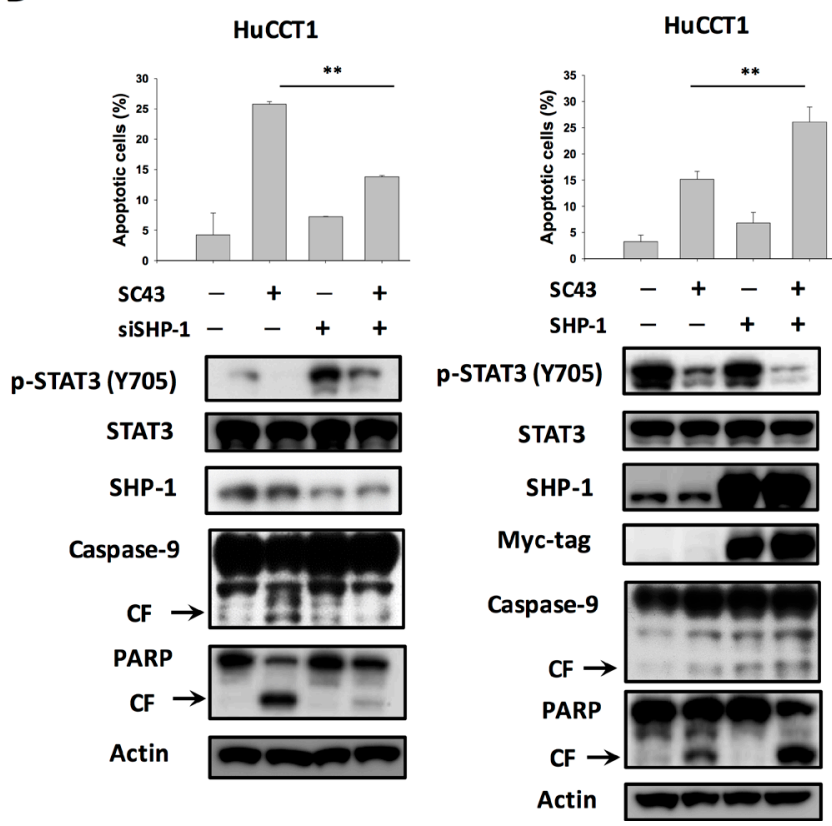

Figure 3: SHP-1/p-STAT3 mediates SC-43-induced apoptosis in CCA cells. SHP-1 plays a role in SC-43-induced STAT3 inhibition and apoptosis. (A) SC-43 increased SHP-1 activity in CCA cells. Cells were treated with SC-43 at the indicated doses for 16 hours. Columns, mean; bars, SD $(n=3)$. $* P<0.05 ; * * P<0.01$. (B) SC-43 activates SHP-1 directly. SC-43 increases the phosphatase activity of SHP-1 in IP-SHP-1 cell lysate from HuCCT-1 cells. Columns, mean; bars, SD $(n=3)$. $* P<0.05 ; * * P<0.01$. (C) Protective effects of SHP-1 specific inhibitor (PTPIII) on SC-43-induced apoptosis in HuCCT-1 and KKU-100 cells. Cells were pretreated with PTPIII at $100 \mathrm{nM}$ for 30 minutes before SC-43 treatment. (D) left, knockdown of SHP-1 reduces the effects of SC-43 on p-STAT3 and apoptosis. HuCCT-1 cells were transfected with control siRNA or SHP-1 siRNA for 24 hours and then treated with SC-43 for another 24 hours. Right, overexpression of SHP-1 induces more apoptosis with SC-43. Apoptotic assay was performed by sub-G1 analysis. Columns, mean; bars, $\mathrm{SD}(n=3) .{ }^{*} P<0.01$. 
of malignant transformation and during further cancer progression [20-25]. IL-6/STAT3 remains a cornerstone factor regulating cholangiocyte growth and survival $[26,27]$. There is a growing body of evidence showing that IL-6/STAT3 signaling is clinically significant in CCA. Banchob et al. revealed that elevated IL-6 level after liver fluke O.viverrini infection correlated with formation of advanced periductal fibrosis, suggesting the importance of IL-6 signaling in CCA formation [13]. The expression of IL6 is upregulated in cancer cells and serum in patients with CCA [28, 29]. Furthermore, expression of STAT3 is associated with poor histological differentiation and adverse prognosis in patients with cholangiocarcinoma [30]. In this study, we demonstrated that p-STAT3 is a major target of SC-43, which is a sorafenib derivative without kinase inhibitor activity in CCA cells. The
A

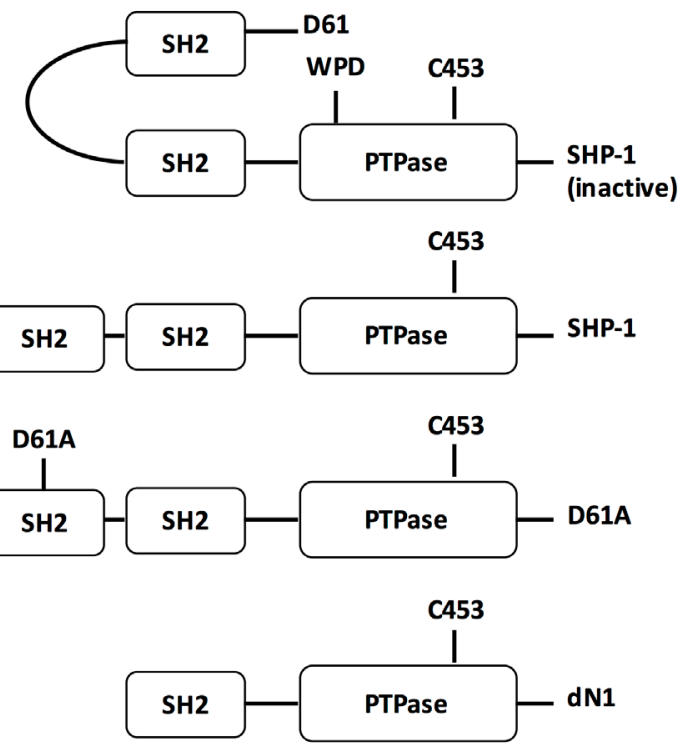

B

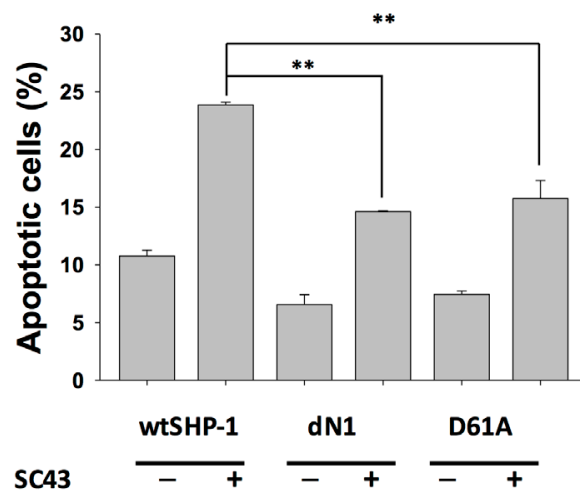

p-STAT3 (Y705)

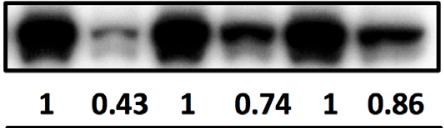

STAT3
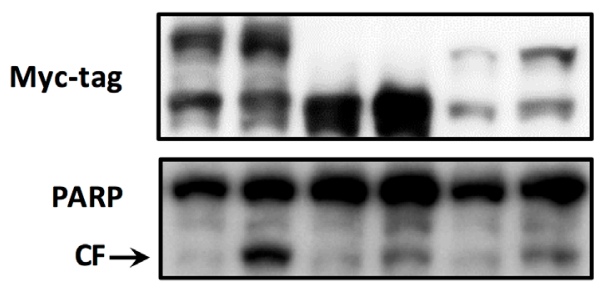

Actin

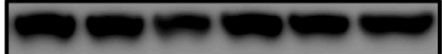

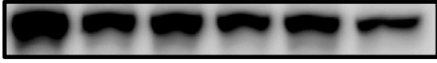

C

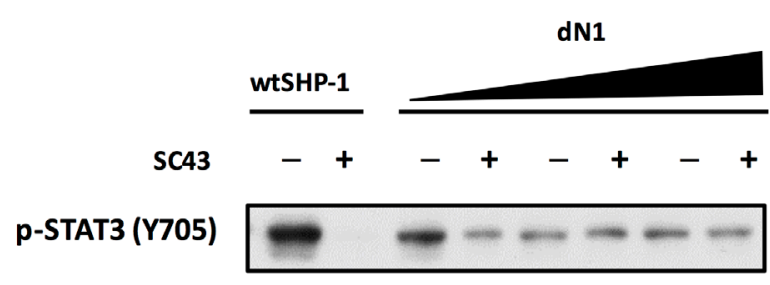

$\begin{array}{llllllll}1 & 0.02 & 0.47 & 0.16 & 0.25 & 0.20 & 0.27 & 0.18\end{array}$

STAT3

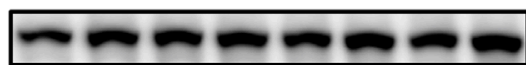

Myc-tag

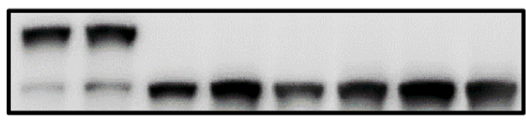

Actin

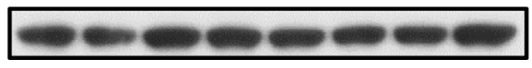

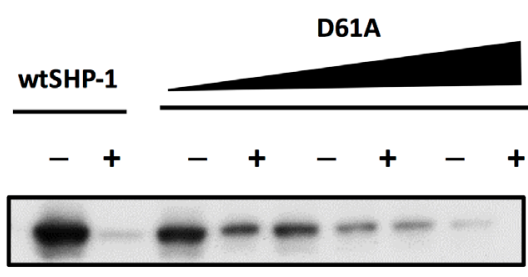

$\begin{array}{llllllll}1 & 0.08 & 0.68 & 0.28 & 0.46 & 0.27 & 0.18 & 0.15\end{array}$
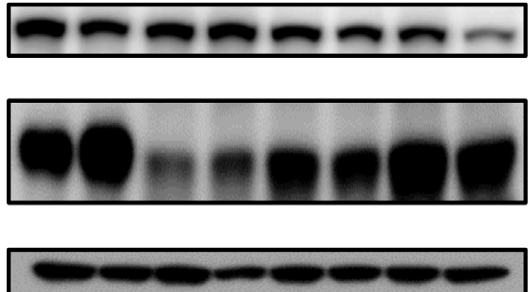

Figure 4: SC-43 activates SHP-1 by relieving the autoinhibition of the SH2 domain. (A) schematic representation of deletion and single mutants of SHP-1. (B) dN1 and D61A impair SC-43-induced STAT3 signaling and apoptotic effect. Apoptotic assay was performed by sub-G1 analysis. Columns, mean; bars, SD $(n=3)$. $* * P<0.01$. (C) dose-dependent dN1 and D61A plasmid transfection suppressed p-STAT3 expression and decreased SC-43-induced p-STAT3 downregulation. 
apoptosis of CCA cells after SC-43 administration is correlated with p-STAT3 downregulation, suggesting that STAT3 is a potential target in treating CCA.

Src homology region 2 (SH2) domain-containing phosphatase 1, SHP-1, acts as a negative regulator of phosphorylated STAT3 (p-STAT3). SHP-1 is a nonreceptor protein tyrosine phosphatase (PTP), composed of two SH2 domains that bind phosphotyrosine, a catalytic PTP domain, and a C-terminal tail. The phosphatase activity of SHP-1 depends on the variation of its 3D structure, as evidenced by its open- or closed-form chemical structure. The N-SH2 domain protrudes into the catalytic domain to directly block the entrance into the active site, and the highly mobile C-SH2 domain is thought to function as an antenna to search for the phosphopeptide activator [31-33]. Previously we demonstrated that SC-43 activates SHP-1 through direct interaction with SHP-1 proteins in HCC cells [18], and this finding was also verified in breast
A

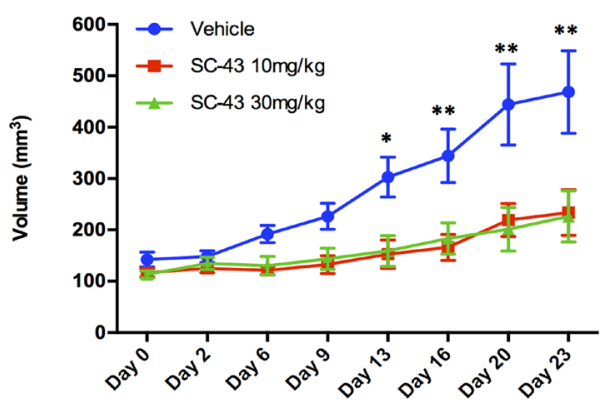

B

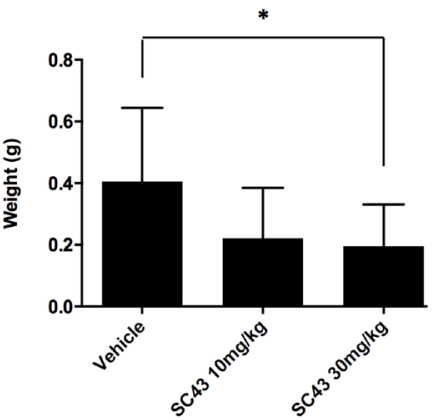

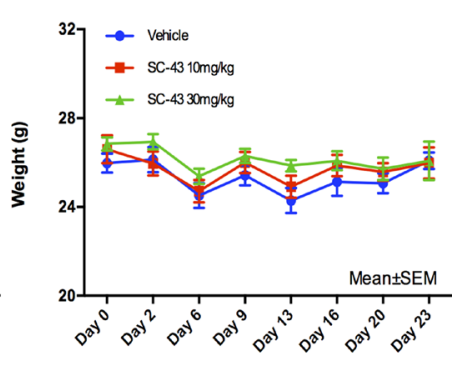
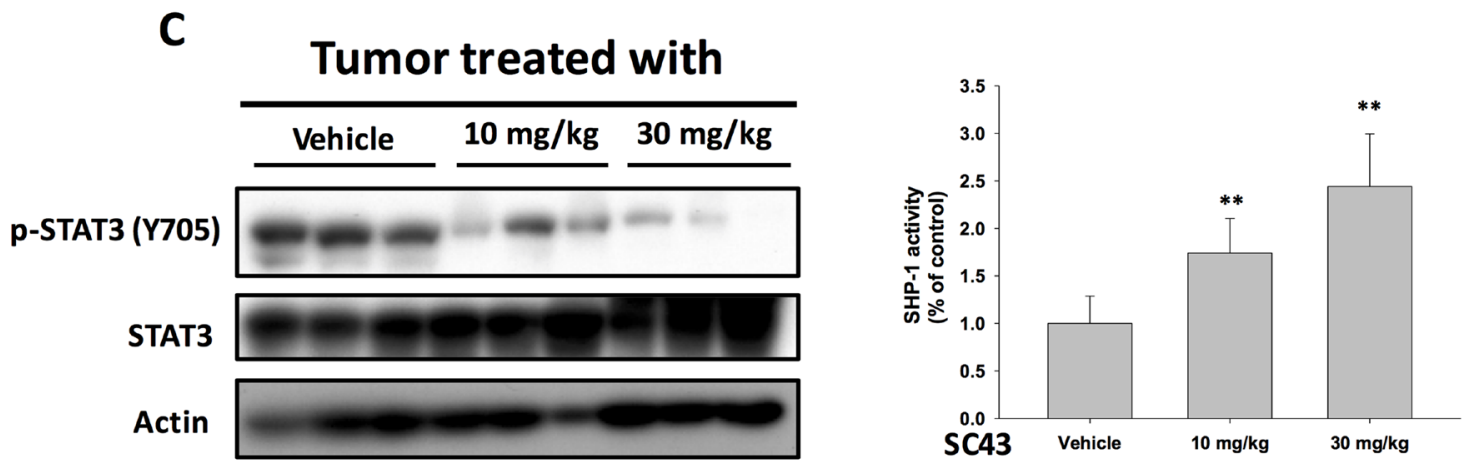

D

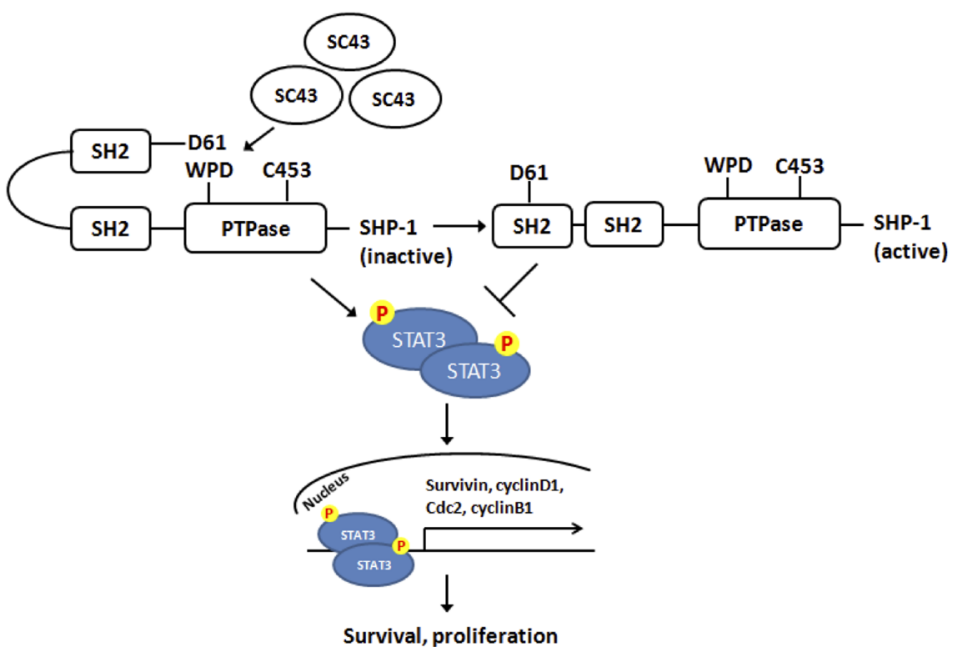

Figure 5: In vivo effects of SC-43 in CCA xenograft animal model. (A) SC-43 exhibited significant tumor growth inhibition in a HuCCT1-bearing CCA subcutaneous model. Left, mice received SC-43 at $10 \mathrm{mg} / \mathrm{kg} /$ day or $30 \mathrm{mg} / \mathrm{kg} /$ day and tumor growth was measured twice weekly. Point, means; bars, SE $(n \geq 9)$. Right, tumor weight at the end of treatment. $* P<0.05$; $* * P<0.01$. (B) Body weight of mice with SC-43 treatment. (C) left, analysis of p-STAT3 and STAT3 in HuCCT1 tumors. Right, SHP-1 phosphatase activity in HuCCT-1 tumors. Columns, mean; bars, SD $(n \geq 6)$. $* * P<0.01$. (D) summary model. SC-43 induced potent apoptosis in CCA by relieving the inhibitory N-SH2 domain of SHP-1 and downregulating p-STAT3, cyclin B1 and Cde2. 
cancer cells [34]. In the study on HCC cells, we provided a molecular docking model that sorafenib and SC-43 docked into the interface of $\mathrm{N}-\mathrm{SH} 2$ and PTPase domain, we hypothesized that sorafenib and SC-43 could bind to the $\mathrm{N}-\mathrm{SH} 2$ domain and subsequently releases and activates the PTPase domain. The interaction of sorafenib (or SC-43) and the N-SH2 domain might lead to a release of the D61 catalytic site and activation of SHP-1 activity [18]. In current study, the hypothesized mechanism of SC-43 was supported by using dN1 (deleted N-SH2) and D61A mutant SHP-1- overexpressing cells; SC-43 exerted less p-STAT3 downregulation and apoptosis-inducing effects in these mutant SHP-1 over-expressing cells, compared to wild-type SHP-1-expressing cells. These results confirmed that the $\mathrm{SH} 2$ domain is a critical docking site of SC-43. However, given the fact that ectopic expression of STAT3 (thus increased p-STAT3) did not completely rescued the SC-43 induced apoptosis (Figure 2C), and that SHP-1 inhibitor PTP3 partially reduced the effect of SC-43 (Figure 3C), it is possible that there may also be other pathways involved in the effect of SC-43 induced apoptosis. Since SC-43 increases SHP-1 activity, it is reasonable that $\mathrm{SC}-43$ induced effects can be mediated by other SHP-1-dependent substrates. Alternatively, other SHP-1 independent pathways may also be involved in SC43 induced effects. More studies are needed to elucidate whether other pathways are also involved in SC-43 induced effects in CCA cells.

It is clear that the cell-cycle checkpoints can regulate the quality and rate of cell division. Agents that can increase G2-M arrest have also been associated with enhanced apoptosis . For example, Jackson et al. [35] demonstrated that the Chk1 indolocarbazole inhibitor (SB218078) enhanced G2-M arrest and cytotoxicity in HeLa cells. Hirose et al. [36] revealed that temozolamide induced G2-M arrest-related apoptosis in glioma cells. With regards to the higher G2-M arrest proportion, we hypothesized that $\mathrm{SC}-43$ induced CCA cells apoptosis through G2-M arrest. In our study, levels of expression of the cyclin B1 and Cdk1 (Cdc2), the major regulatory protein and kinase for progression from $\mathrm{G} 2$ to $\mathrm{M}$ phase were markedly reduced after SC-43 treatment. It is known that STAT3 signaling axis induced cell proliferation through binding to cdc2 [23, $37,38]$. Furthermore, STAT3 promotes mitosis process primarily by stimulating transcription of cyclin B1 and other regulatory proteins, such as c-myc and cyclin D1 [39-43]. In our presenting study, SC-43 induces apoptosis with downregulation of STAT3 in sensitive CCA cells. In addition, $\mathrm{SC}-43$ promotes $\mathrm{G} 2-\mathrm{M}$ arrest by reducing transcription level of cyclin $\mathrm{B} 1$ and $\mathrm{Cdc} 2$ protein.

SHP-1 is predominantly expressed in hematopoietic and epithelial cells. Notably, SHP-1 generally acts as a negative regulator in a variety of cellular signaling pathways [44, 45]. However, the underlying molecular mechanism by which SHP-1 is involved in carcinogenesis is not completely understood. Some studies have indicated that SHP-1 is a potential tumor suppressor gene in cancer formation [46-49]. However, the clinical value of cancer treatment by targeting SHP-1 is still under investigation. According to a few reports [50-52], several agents that regulate SHP-1 activity have been identified, and some have found efficacy against different cancer cells. In our previous work, we disclosed that regorafenib, a multiple protein kinase inhibitor, exerts anti-tumor effects by enhancing SHP-1 activity [50]. Dovitinib, another multiple protein kinase inhibitor, acts as a novel radiosensitizer in HCC by upregulating SHP-1 [51]. Moreover, SHP-1 activation by a novel Bcl-2 inhibitor derivative was found to induce HCC autophagy [52]. In the present study, we demonstrated that SC-43 has a SHP-1-dependent apoptotic effect in CCA cells. Therefore, our data strengthen the rationale for targeting the SHP-1/STAT3 pathway as a novel anti-cancer therapy. Taken together, these structurally unrelated agents show a common target in various cancer cells suggesting that SHP-1 may be a potential therapeutic target.

In this study, a total of 40 cases with pathologically confirmed CCA were analyzed in this study. About half $(21$ of $40,52.5 \%)$ of the specimens revealed only weak positive p-STAT3 expression. We have added Supplementary Figure 2 showing some examples of weakstaining p-STAT3 in our CCA samples (Supplementary Figure 2) There are several possible reasons for the relatively low p-STAT3 expression in current study. First, the protein phosphorylation is usually dynamic and rapidly degraded. Second, the level of phosphorylated protein is relatively limited and difficultly detected. Third, the limitation of IHC for FFPE tissue due to the adverse influence of formalin upon antigenicity and the great variation in processing procedures. Fourth, in this retrospective study, some specimens have been preserved for more than ten years, therefore the quality of IHC in these FFPE tissue is inevitably diminished.

\section{MATERIALS AND METHODS}

\section{Reagents and antibodies}

SC-43 was dissolved in dimethyl sulfoxide and then added to the cells maintained in RPMI 1640 medium without FBS. SHP-1 inhibitor (PTPIII) was purchased from Calbiochem. Antibodies, such as cyclin D1, STAT3, phospho-STAT3 (Tyr705), survivin, and caspase-9 were purchased from Cell Signaling (Danvers, MA). Other antibodies, such as cyclin B1 and Cdc2 were purchased from Abcam (London).

\section{Cell culture and western blot analysis}

The HuCCT-1 cell line was purchased from Riken BRC (Riken BioResource Center) (Saitama, Japan). The KKU-100 cell line was obtained from JCRB Cell Bank (Japanese Collection of Research Bioresources Cell 
Bank) (Osaka, Japan). The CGCCA cell line was kindly provided by Taipei Veterans General Hospital. HuCCT-1 cells was routinely cultured in RPMI 1640 (Invitrogen/ Life Technologies, Saint Aubin, France), while KKU-100 and CGCCA cells were cultured in Dulbecco's modified Eagle's medium (Gibco/Life Technologies, Grand Island, NY, USA). All CCA cells were supplemented with 10\% heat-inactivated fetal bovine serum (Gibco/ Life Technologies, Grand Island, NY, USA), $100 \mu \mathrm{g} /$ $\mathrm{mL}$ streptomycin sulfate, and $100 \mu \mathrm{g} / \mathrm{mL}$ penicillin, in a humidified atmosphere containing $5 \% \mathrm{CO}_{2}$ at $37^{\circ} \mathrm{C}$.

Lysates of CCA cells treated with drugs at the indicated concentrations for various periods of time were prepared for immunoblotting of p-STAT3, STAT3, etc.

Whole-cell lysates were resolved by sodium dodecyl sulfate polyacrylamide gel electrophoresis. Proteins were transferred onto a polyvinylidene difluoride membrane (Millipore, Billerica, MA, USA) and incubated with the primary antibody, and then incubated with horseradish peroxidase-conjugated secondary antibodies. Specific proteins were detected using enhanced chemiluminescence reagent.

\section{Cell viability and proliferation of CCA cell lines in vitro}

Cell viability and proliferation of CCA cells treated with or without SC-43 were assessed by colorimetric assay using 3-(4,5-dimethylthiazol-2-yl)-2,5 diphenyltetrazolium bromide (MTT). Cells were plated in a 96-well plate in $100 \mu \mathrm{l}$ DMEM per well and cultured for up to 72 hours. Cells were incubated for four hours at $37^{\circ} \mathrm{C}$ with MTT; after incubation, medium was removed and cells were treated with dimethyl sulfoxide (DMSO) for five minutes. Viability was evaluated by ultraviolet absorption spectrum at $540 \mathrm{~nm}$ with a Microplate Reader Model 550 (Bio-Rad, Richmond, CA, USA). Experiments were performed three times in duplicate.

\section{Apoptosis analysis}

Drug-induced apoptotic cell death was assessed by measuring apoptotic cells by flow cytometry (sub-G1 analysis of propidium iodide-stained cells) and western blot analysis of caspase 3 cleavage.

\section{Generation of CCA cells with ectopically expressed STAT3}

STAT3 cDNA (KIAA1524) were purchased from Addgene plasmid repository (http://www.addgene.org/). HuCCT-1 cells with ectopic expression of STAT3 derived from a single-stable clone were prepared for in vitro assay for STAT3 target validation. Briefly, following transfection as previously prescribed [19], HuCCT-1 was incubated in the presence of G418 $(0.78 \mathrm{mg} / \mathrm{ml})$. After 8 weeks of selection, surviving colonies, i.e., those arising from stably transfected cells, were selected and individually amplified. Control cells were transfected by empty vectors.

\section{Gene knockdown using siRNA}

Smart-pool siRNAs, including control (D-001810 10), SHP-1 (PTPN6, L-009778- 00-0005), and STAT3 were all purchased from Dharmacon (Chicago, IL, USA). Plasmids of human wild-type STAT3 and SHP-1 (PTPN6) were encoded by pCMV6 vector with myc-tag. For mutant-type SHP-1 expression, we generated two plasmids, designated $\mathrm{dN} 1$ and D61A, with a truncated $\mathrm{N}-\mathrm{SH} 2 / \mathrm{PTP}$ domain and aspartic acid at 61 changed to an alanine residue, respectively. Both plasmids were cloned into pCMV6 entry vector. These plasmids or siRNAs were subsequently transfected into cells by using Lipofectamine 2000 Reagent (Invitrogen, CA, USA).

\section{SHP-1 phosphatase activity assay}

After treatment of SC-43, the cellular protein extracts were incubated with anti-SHP-1 antibody in immunoprecipitation buffer $(20 \mathrm{mM}$ of Tris- $\mathrm{HCl}$ [pH 7.5], $150 \mathrm{mM}$ of $\mathrm{NaCl}, 1 \mathrm{mM}$ of ethylenediaminetetraacetic acid, $1 \%$ NP-40, and $1 \%$ sodium deoxycholate) overnight. Protein G-Sepharose 4 Fast flow (GE Healthcare BioScience, NJ, USA) was added to each sample, followed by incubation for $3 \mathrm{~h}$ at $4^{\circ} \mathrm{C}$ with rotation. A RediPlate 96 EnzChekR Tyrosine Phosphatase Assay Kit (R-22067) was used for SHP-1 activity assay (Molecular Probes, Invitrogen, CA, USA).

\section{Xenograft tumor growth}

Male NCr athymic nude mice (5-7 weeks of age) were obtained from the National Laboratory Animal Center (Taipei, Taiwan, ROC). The mice were housed in groups and maintained in an SPF-environment. All experimental procedures using these mice were performed in accordance with protocols approved by the Institutional Animal Care and Use Committee of Cardinal Tien Hospital. Each mouse was inoculated orthotopically to the mouse mammary pads with $5 \times 10^{6}$ HuCCT- 1 cells suspended in $0.1 \mathrm{~mL}$ serum-free medium containing $50 \%$ Matrigel (BD Biosciences, Bedford, MA) under isoflurane anesthesia. Tumors were measured using calipers and their volumes calculated using a standard formula: width $^{2} \times$ length $\times 0.52$. When tumors reached around $100 \mathrm{~mm}^{3}$, mice were administered orally with SC-43 at $10 \mathrm{mg} / \mathrm{kg}$ or $30 \mathrm{mg} / \mathrm{kg}$ daily by oral gavage. Controls received vehicle ( $1 \times$ phosphate buffered saline). Upon termination of treatment, mice were sacrificed and xenografted tumors were harvested and assayed for tumor weight, SHP-1 activity, and molecular events by western blot analysis. 


\section{Immunohistochemistry}

Immunohistochemical (IHC) stains were performed, using the Ventana BenchMark XT automated stainer (Ventana, Tucson, AZ, USA). Briefly speaking, 4- $\mu \mathrm{m}$ thick sections would be cut consecutively from formalin-fixed, paraffin-embedded (FFPE) human tissue. Sections would be mounted and allowed to dry overnight at $37^{\circ} \mathrm{C}$. After deparaffinization and rehydration, slides would be incubated with $3 \%$ hydrogen peroxide solution for 5 minutes. After a washing procedure with the supplied buffer, tissue sections were repaired for 40 minutes with ethylenediamine tetraacetic acid. The slides were then incubated with primary antibodies against p-STAT3 (1:50; Cell Signaling) for 60 minutes at $37^{\circ} \mathrm{C}$ and overnight at $4{ }^{\circ} \mathrm{C}$. Negative control slides processed without the primary antibody were included for each staining. After three rinses in buffer, the slides were incubated with the secondary antibodies (unbiotinylated antibody; EnVisionTM System; HRP, anti-mouse/rabbit, DakoCytomation; Dako, Glostrup, Denmark). Tissue staining were visualized with a 3,3'-diaminobenzidine (DAB) substrate chromogen solution (DakoCytomation). Slides were counterstained with hematoxylin, dehydrated, and mounted. Samples which express these markers strongly served as the positive controls. The mean percentage of positive tumor cells was determined in at least five areas at $\times 200$ magnification. All slides were evaluated by experienced pathologists who reviewed the slides together and reached a consensus. Positive expression for p-STAT3 was defined as $>25 \%$ nuclear staining with greater than moderate staining intensity of tumor cells.

\section{Statistical analysis}

All data are expressed as mean \pm SD or SE. Statistical comparisons were based on nonparametric tests. $P$ value less than 0.05 was defined as statistical significance. All statistical analyses were performed using SPSS for Windows software, version 19.0 (SPSS, Chicago, IL, USA).

\section{CONCLUSIONS}

Novel sorafenib derivative, SC-43, exerts a G2-M arrest and anti-proliferative effect on CCA cells through a SHP-1-dependent STAT3 downregulation pathway by interrupting SHP-1 auto-inhibition. This study reinforced the hypothesis that targeting STAT3 in this inflammatory malignancy may be a useful therapeutic strategy, and provides an innovative approach to CCA management. Further study is warranted to explore the details of the SHP-1/STAT3 pathway in the development of disruptive molecular-targeted therapy for CCA.

\section{CONFLICTS OF INTEREST}

The authors declare no conflicts of interest.

\section{FUNDING}

This study was supported by grants from National Health Research Institutes (NHRI-EX106-10608BI) and Cardinal Tien Hospital (CTH-104-2-2A02).

\section{REFERENCES}

1. Welzel TM, McGlynn KA, Hsing AW, O'Brien TR, Pfeiffer RM. Impact of classification of hilar cholangiocarcinomas (Klatskin tumors) on the incidence of intra- and extrahepatic cholangiocarcinoma in the United States. J Natl Cancer Inst. 2006; 98:873-75.

2. Taylor-Robinson SD, Toledano MB, Arora S, Keegan TJ, Hargreaves S, Beck A, Khan SA, Elliott P, Thomas HC. Increase in mortality rates from intrahepatic cholangiocarcinoma in England and Wales 1968-1998. Gut. 2001; 48:816-20.

3. Patel T. Increasing incidence and mortality of primary intrahepatic cholangiocarcinoma in the United States. Hepatology. 2001; 33:1353-57.

4. Khan SA, Taylor-Robinson SD, Toledano MB, Beck A, Elliott P, Thomas HC. Changing international trends in mortality rates for liver, biliary and pancreatic tumours. J Hepatol. 2002; 37:806-13.

5. Everhart JE, Ruhl CE. Burden of digestive diseases in the United States Part III: Liver, biliary tract, and pancreas. Gastroenterology. 2009; 136:1134-44.

6. Tyson GL, El-Serag HB. Risk factors for cholangiocarcinoma. Hepatology. 2011; 54:173-84.

7. Sripa B, Pairojkul C. Cholangiocarcinoma: lessons from Thailand. Curr Opin Gastroenterol. 2008; 24:349-56.

8. Shaib Y, El-Serag HB. The epidemiology of cholangiocarcinoma. Semin Liver Dis. 2004; 24:115-25.

9. Palmer WC, Patel T. Are common factors involved in the pathogenesis of primary liver cancers? A meta-analysis of risk factors for intrahepatic cholangiocarcinoma. J Hepatol. 2012; 57:69-76.

10. Gores GJ. Cholangiocarcinoma: current concepts and insights. Hepatology. 2003; 37:961-69.

11. Parkin DM, Srivatanakul P, Khlat M, Chenvidhya D, Chotiwan P, Insiripong S, L'Abbé KA, Wild CP. Liver cancer in Thailand. I. A case-control study of cholangiocarcinoma. Int J Cancer. 1991; 48:323-28.

12. Honjo S, Srivatanakul P, Sriplung H, Kikukawa H, Hanai S, Uchida K, Todoroki T, Jedpiyawongse A, Kittiwatanachot P, Sripa B, Deerasamee S, Miwa M. Genetic and environmental determinants of risk for cholangiocarcinoma via Opisthorchis viverrini in a densely infested area in Nakhon Phanom, northeast Thailand. Int J Cancer. 2005; 117:854-60.

13. Sripa B, Mairiang E, Thinkhamrop B, Laha T, Kaewkes S, Sithithaworn P, Tessana S, Loukas A, Brindley PJ, Bethony JM. Advanced periductal fibrosis from infection with the carcinogenic human liver fluke Opisthorchis viverrini 
correlates with elevated levels of interleukin-6. Hepatology. 2009; 50:1273-81.

14. Schuringa JJ, Wierenga AT, Kruijer W, Vellenga E. Constitutive Stat3, Tyr705, and Ser727 phosphorylation in acute myeloid leukemia cells caused by the autocrine secretion of interleukin-6. Blood. 2000; 95:3765-70.

15. Meng F, Wehbe-Janek H, Henson R, Smith H, Patel T. Epigenetic regulation of microRNA-370 by interleukin- 6 in malignant human cholangiocytes. Oncogene. 2008; 27:378-86.

16. Landskron G, De la Fuente M, Thuwajit P, Thuwajit C, Hermoso MA. Chronic inflammation and cytokines in the tumor microenvironment. J Immunol Res. 2014; 2014:149185.

17. Blechacz BR, Smoot RL, Bronk SF, Werneburg NW, Sirica AE, Gores GJ. Sorafenib inhibits signal transducer and activator of transcription-3 signaling in cholangiocarcinoma cells by activating the phosphatase shatterproof 2 . Hepatology. 2009; 50:1861-70.

18. Tai WT, Shiau CW, Chen PJ, Chu PY, Huang HP, Liu CY, Huang JW, Chen KF. Discovery of novel Src homology region 2 domain-containing phosphatase 1 agonists from sorafenib for the treatment of hepatocellular carcinoma. Hepatology. 2014; 59:190-201.

19. Tai WT, Cheng AL, Shiau CW, Huang HP, Huang JW, Chen PJ, Chen KF. Signal transducer and activator of transcription 3 is a major kinase-independent target of sorafenib in hepatocellular carcinoma. J Hepatol. 2011; 55:1041-48.

20. Mantovani A, Allavena P, Sica A, Balkwill F. Cancer-related inflammation. Nature. 2008; 454:436-44.

21. Catlett-Falcone R, Landowski TH, Oshiro MM, Turkson J, Levitzki A, Savino R, Ciliberto G, Moscinski L, FernándezLuna JL, Nuñez G, Dalton WS, Jove R. Constitutive activation of Stat 3 signaling confers resistance to apoptosis in human U266 myeloma cells. Immunity. 1999; 10:105-15.

22. Yu H, Lee H, Herrmann A, Buettner R, Jove R. Revisiting STAT3 signalling in cancer: new and unexpected biological functions. Nat Rev Cancer. 2014; 14:736-46.

23. Bollrath J, Phesse TJ, von Burstin VA, Putoczki T, Bennecke M, Bateman T, Nebelsiek T, Lundgren-May T, Canli O, Schwitalla S, Matthews V, Schmid RM, Kirchner T, et al. gp130-mediated Stat3 activation in enterocytes regulates cell survival and cell-cycle progression during colitisassociated tumorigenesis. Cancer Cell. 2009; 15:91-102.

24. Hirano T, Ishihara K, Hibi M. Roles of STAT3 in mediating the cell growth, differentiation and survival signals relayed through the IL-6 family of cytokine receptors. Oncogene. 2000; 19:2548-56.

25. Yu H, Pardoll D, Jove R. STATs in cancer inflammation and immunity: a leading role for STAT3. Nat Rev Cancer. 2009; 9:798-809.

26. Matsumoto K, Fujii H, Michalopoulos G, Fung JJ, Demetris AJ. Human biliary epithelial cells secrete and respond to cytokines and hepatocyte growth factors in vitro: interleukin-6, hepatocyte growth factor and epidermal growth factor promote DNA synthesis in vitro. Hepatology. 1994; 20:376-82.

27. Meng F, Yamagiwa Y, Ueno Y, Patel T. Over-expression of interleukin-6 enhances cell survival and transformed cell growth in human malignant cholangiocytes. J Hepatol. 2006; 44:1055-65.

28. Yokomuro S, Tsuji H, Lunz JG 3rd, Sakamoto T, Ezure T, Murase N, Demetris AJ. Growth control of human biliary epithelial cells by interleukin 6, hepatocyte growth factor, transforming growth factor beta1, and activin A: comparison of a cholangiocarcinoma cell line with primary cultures of non-neoplastic biliary epithelial cells. Hepatology. 2000; 32:26-35.

29. Nehls O, Gregor M, Klump B. Serum and bile markers for cholangiocarcinoma. Semin Liver Dis. 2004; 24:139-54.

30. Dokduang $H$, Techasen A, Namwat N, Khuntikeo N, Pairojkul C, Murakami Y, Loilome W, Yongvanit P. STATs profiling reveals predominantly-activated STAT3 in cholangiocarcinoma genesis and progression. J Hepatobiliary Pancreat Sci. 2014; 21:767-76.

31. Yang J, Liang X, Niu T, Meng W, Zhao Z, Zhou GW. Crystal structure of the catalytic domain of protein-tyrosine phosphatase SHP-1. J Biol Chem. 1998; 273:28199-207.

32. Yang J, Liu L, He D, Song X, Liang X, Zhao ZJ, Zhou GW. Crystal structure of human protein-tyrosine phosphatase SHP-1. J Biol Chem. 2003; 278:6516-20.

33. Wang W, Liu L, Song X, Mo Y, Komma C, Bellamy HD, Zhao ZJ, Zhou GW. Crystal structure of human protein tyrosine phosphatase SHP-1 in the open conformation. J Cell Biochem. 2011; 112:2062-71.

34. Liu CY, Tseng LM, Su JC, Chang KC, Chu PY, Tai WT, Shiau CW, Chen KF. Novel sorafenib analogues induce apoptosis through SHP-1 dependent STAT3 inactivation in human breast cancer cells. Breast Cancer Res. 2013; 15:R63.

35. Jackson JR, Gilmartin A, Imburgia C, Winkler JD, Marshall LA, Roshak A. An indolocarbazole inhibitor of human checkpoint kinase (Chk1) abrogates cell cycle arrest caused by DNA damage. Cancer Res. 2000; 60:566-72.

36. Hirose Y, Berger MS, Pieper RO. Abrogation of the Chk1-mediated $G(2)$ checkpoint pathway potentiates temozolomide-induced toxicity in a p53-independent manner in human glioblastoma cells. Cancer Res. 2001; 61:5843-49.

37. O'Connor DS, Grossman D, Plescia J, Li F, Zhang H, Villa A, Tognin S, Marchisio PC, Altieri DC. Regulation of apoptosis at cell division by $\mathrm{p} 34 \mathrm{cdc} 2$ phosphorylation of survivin. Proc Natl Acad Sci USA. 2000; 97:13103-07.

38. Altieri DC. Survivin, cancer networks and pathway-directed drug discovery. Nat Rev Cancer. 2008; 8:61-70.

39. Jarnicki A, Putoczki T, Ernst M. Stat3: linking inflammation to epithelial cancer - more than a "gut" feeling? Cell Div. 2010; 5:14. 
40. Liu T, Peng H, Zhang M, Deng Y, Wu Z. Cucurbitacin B, a small molecule inhibitor of the Stat3 signaling pathway, enhances the chemosensitivity of laryngeal squamous cell carcinoma cells to cisplatin. Eur J Pharmacol. 2010; 641:15-22.

41. Bromberg JF, Wrzeszczynska MH, Devgan G, Zhao Y, Pestell RG, Albanese C, Darnell JE Jr. Stat3 as an oncogene. Cell. 1999; 98:295-303.

42. Masuda M, Suzui M, Yasumatu R, Nakashima T, Kuratomi Y, Azuma K, Tomita K, Komiyama S, Weinstein IB. Constitutive activation of signal transducers and activators of transcription 3 correlates with cyclin D1 overexpression and may provide a novel prognostic marker in head and neck squamous cell carcinoma. Cancer Res. 2002; 62:3351-55.

43. Bowman T, Broome MA, Sinibaldi D, Wharton W, Pledger WJ, Sedivy JM, Irby R, Yeatman T, Courtneidge SA, Jove R. Stat3-mediated Myc expression is required for $\mathrm{Src}$ transformation and PDGF-induced mitogenesis. Proc Natl Acad Sci USA. 2001; 98:7319-24.

44. Neel BG, Tonks NK. Protein tyrosine phosphatases in signal transduction. Curr Opin Cell Biol. 1997; 9:193-204.

45. Barford D, Neel BG. Revealing mechanisms for SH2 domain mediated regulation of the protein tyrosine phosphatase SHP-2. Structure. 1998; 6:249-54.

46. Hegazy SA, Wang $\mathrm{P}$, Anand M, Ingham RJ, Gelebart $\mathrm{P}$, Lai R. The tyrosine 343 residue of nucleophosmin (NPM)anaplastic lymphoma kinase (ALK) is important for its interaction with SHP1, a cytoplasmic tyrosine phosphatase with tumor suppressor functions. J Biol Chem. 2010; 285:19813-20.
47. Witkiewicz A, Raghunath P, Wasik A, Junkins-Hopkins JM, Jones D, Zhang Q, Odum N, Wasik MA. Loss of SHP-1 tyrosine phosphatase expression correlates with the advanced stages of cutaneous T-cell lymphoma. Hum Pathol. 2007; 38:462-67.

48. Hayslip J, Montero A. Tumor suppressor gene methylation in follicular lymphoma: a comprehensive review. Mol Cancer. 2006; 5:44.

49. Chim CS, Wong KY, Loong F, Srivastava G. SOCS1 and SHP1 hypermethylation in mantle cell lymphoma and follicular lymphoma: implications for epigenetic activation of the Jak/STAT pathway. Leukemia. 2004; 18:356-58.

50. Fan LC, Teng HW, Shiau CW, Lin H, Hung MH, Chen YL, Huang JW, Tai WT, Yu HC, Chen KF. SHP-1 is a target of regorafenib in colorectal cancer. Oncotarget. 2014; 5:6243-51. https://doi.org/10.18632/oncotarget.2191.

51. Huang CY, Tai WT, Wu SY, Shih CT, Chen MH, Tsai MH, Kuo CW, Shiau CW, Hung MH, Chen KF. Dovitinib Acts As a Novel Radiosensitizer in Hepatocellular Carcinoma by Targeting SHP-1/STAT3 Signaling. Int J Radiat Oncol Biol Phys. 2016; 95:761-71.

52. Su JC, Tseng PH, Hsu CY, Tai WT, Huang JW, Ko CH, Lin MW, Liu CY, Chen KF, Shiau CW. RFX1-dependent activation of SHP-1 induces autophagy by a novel obatoclax derivative in hepatocellular carcinoma cells. Oncotarget. 2014; 5:4909-19. https://doi.org/10.18632/oncotarget.2054. 